\title{
Editorial
}

Anllergy
Imternationa Archive of
Immunology

\section{Histamine and Its Relation to Allergens in the Skin Prick Test}

\author{
Christian Möller \\ University of Umeå, Umeå, Sweden
}

It is obvious to a clinician that the skin reactivity as measured with histamine pricks varies. Studies have shown that age [1,2], immunotherapy [3], habitat [4] and menstrual cycle [5] influence the size of the prick. The more positive allergen skin prick tests, the bigger the histamine wheal $[6,7]$. In pollen-allergic patients, the sensitivity of the shock organ varies over the year [8], and probably also the skin sensitivity to the offending allergen, but to histamine as well to some degree, shows similar changes [9]. The skin sensitivity appears to have been increasing from year to year [10]. Antihistamines have an enormous influence on the histamine wheal, while other drugs, e.g. oral corticosteroids, do not show the same effect; most drugs are not studied but are probably not important when evaluating skin prick tests. Circadian rhythm [11], sex, stress, ethnicity, shock organ and environmental exposure to irritants are other factors which might influence skin sensitivity but have to my knowledge not been properly studied. Different techniques when doing skin prick testing change results considerably [12]. The body region used for testing as well as the distance between pricks may influence wheal sizes [13]. The pricking device is important [14-17]. The concentration of histamine used for positive control is important $[18,19]$ but is not further discussed here as the EAACI has decided to use histamine $10 \mathrm{mg} / \mathrm{ml}$ as a positive reference [20]. When the negative control does not give a wheal, it seems plausible that the skin reactivity to histamine correlates to the sensitivity to the tested allergens. If so, the skin reaction to histamine tells us how to interpret the allergen pricks.
(C) 2015 S. Karger AG, Basel

$1018-2438 / 15 / 1664-0241 \$ 39.50 / 0$
The EAACI recommends that the positive control, i.e. the histamine prick, could be used only to prove that the skin can react [20]. This means that the size of the allergen wheals are to be understood irrespective of the precise size of the histamine wheal. However, others have had a hunch that sizes of the allergen wheals must be dependent of the skin sensitivity and that this sensitivity could be measured with histamine pricks. Thus, the older Nordic Standard recommended that the allergen wheals and that of histamine should be correlated [21], albeit the way of doing this was not very precise.

If the EAACI in practice does not care about the skin reactivity while the Nordic Standard does but in a rather inaccurate way, does it matter which recommendations we follow? The dose-response curve for allergens and histamine is very flat and differences in sensitivity thus difficult to detect with imprecise methods [19]. In a multinational study of sensitization where case history was correlated to skin prick testing [22], we looked at this and found that the results for the whole group were similar irrespective of the evaluation method [unpublished]. However, we were only interested in possible sensitization as defined in the study and not in the degree of sensitization. In such a study, it did not matter much which method was chosen, and it shows that the methods are comparable in clinical practice if the only interest is whether the patient is sensitized or not.

The present study by Dreborg [12] clearly shows that it is necessary to correlate the allergen wheals to the skin reactivity, e.g. as measured with histamine, if these siz-
Correspondence to: Dr. Christian Möller

Vedebyvägen 73

SE-640 20 Björkvik (Sweden)

E-Mail christian.moller@one.se 
es in a fairly precise way are meant to show the degree of sensitization. The trial was done several years ago, and it is a pity that it has not been commonly known until now. Too many investigators have used the changes in the size of allergen wheals as an outcome of intervention without mentioning what has happened to the histamine wheal during the same time. It is especially important in multicenter studies and if different persons are performing the skin prick test at different times.

It is an important message that if the size of allergen wheals in skin prick testing should be used as an outcome measure, they must be correlated to the skin sensitivity measured with histamine in all scientific work.

\section{References}

1 Hanneuse Y, Delespesse G, Hudson D, de Halleux F, Jacques JM: Influence of ageing on IgE-mediated reactions in allergic patients. Clin Allergy 1978;8:65-74.

-2 Skassa-Brociek W, Manderscheid JC, Michel $\mathrm{FB}$, Bousquet J: Skin test reactivity to histamine from infancy to old age. J Allergy Clin Immunol 1987;80:711-716.

>3 Möller C, Dreborg S: Crossreactivity between deciduous trees during immunotherapy. I. In vivo results. Clin Allergy 1986;16:135-144.

4 Ronchetti R, Haluszka J, Martella S, et al: Skin reactivity to histamine and to allergens in unselected 9-year-old children living in Poland and Italy. Pediatr Allergy Immunol 2003;14: 201-206.

$>5$ Kalogeromitros D, Katsarou A, Armenika M, et al: Influence of the menstrual cycle on skinprick reactions to histamine, morphine and allergen. Clin Exp Allergy 1995;25:461-466.

6 Stuckey MS, Witt CS, Schmitt LH, Warlow R, Lattimore M, Dawkins RL: Histamine sensitivity influences reactivity to allergens. J Allergy Clin Immunol 1985;75:373-376.

$>7$ Kidon MI, See Y, Bun CY, et al: Bimodial skin reactivity to histamine in atopic children in Singapore: influence of specific sensitizations. Pediatr Allergy Immunol 2004;15:545-550.
8 Möller C, Elsayed S: Seasonal variation of the conjunctival provocation test, total IgE and birch-specific IgE in children with birch pollinosis. Int Arch Allergy Appl Immunol 1990; 92:306-308.

$\checkmark 9$ Haahtela T, Jokela H: Influence of the pollen season on immediate skin test reactivity to common allergens. Allergy 1980;35:15-21.

-10 Ronchetti R, Pia Villa M, Ciofetta G, Barreto M, Falasca C, Martella S: Changes over 13 years in skin reactivity to histamine in cohorts of children aged 9-13 years. Allergy 2001;56: 436-441.

11 Guilherme A, Duarte R, Santos A, Figueiredo Pinto A: Circadian rhythm of cutaneous reactivity. Poster from Hospital Santos Silva, Vila Nova de Gaia, Portugal.

12 Dreborg S: Allergen skin prick test should be adjusted by the histamine reactivity. Int Arch Allergy Immunol 2015;166:77-80.

13 Nelson HS, Knoetzer J, Bucher B: Effect of distance between sites and region of the body on results of skin prick tests. J Allergy Clin Immunol 1996;97:596-601.

14 Nelson HS, Rosloniec DM, McCall LI, Ikle D: Comparative performance of five commercial prick skin test devices. J Allergy Clin Immunol 1993;92:750-756.

15 Rizzo MC, Naspitz CK, Sole D: Comparative performance for immediate hypersensitivity skin testing using two skin prick test devices. J Investig Allergol Clin Immunol 1995;5:354356.
16 Nelson HS, Lahr J, Buchmeier A, McCormick D: Evaluation of devices for skin prick testing J Allergy Clin Immunol 1998;101:153-156.

17 Illi S, Garcia-Marcos L, Hernando V, Guillen JJ, Liese A, von Mutius E: Reproducibility of skin prick test results in epidemiologic studies: a comparison of two devices. Allergy 1998; 53:353-358.

18 Malling HJ: Skin prick testing and the use of histamine references. Allergy 1984;39:596601.

19 Dreborg S, Holgersson M, Nilsson G, Zetterstrom O: Dose response relationship of allergen, histamine, and histamine releasers in skin prick test and precision of the skin prick test method. Allergy 1987;42:117-125.

20 The European Academy of Allergology and Clinical Immunology. Position paper: allergen standardization and skin tests. Allergy 1993;48:48-82.

21 Aas K, Belin L: Standardization of diagnostic work in allergy. Int Arch Allergy Appl Immunol 1973;45:57-60.

22 Eriksson NE, Holmén A, Möller C, Wihl J-A: Sensitization according to skin prick testing in atopic patients with asthma or rhinitis at 24 allergy clinics in Northern Europe and Asia. Allergol Int 1998;47:187-196. 